\title{
Fobia sosial Tokoh Satou Tatsuhiro dalam Manga NHK ni Youkoso! Karya Takimoto Tatsuhiko
}

\author{
Theresia Valentina Arwanto $^{1^{*}}$, I Made Budiana ${ }^{2}$, Ni Luh Putu Ari Sulatri ${ }^{3}$ \\ ${ }^{[123]}$ Prodi Sastra Jepang Fakultas Ilmu Budaya Unud \\ 1email: therethesya@gmail.com] 2[budi.hybrid@gmail.com] \\ [ari_sulatri@unud.ac.id] \\ *Corresponding Author
}

\begin{abstract}
Abstrak
Penelitian ini berjudul "Fobia Sosial tokoh Satou Tatsuhiro dalam Manga NHK ni Youkoso! karya Takimoto Tatsuhiko". Penelitian ini bertujuan untuk mengetahui gejala, faktor penyebab, dan upaya mengatasi fobia sosial tokoh Satou Tatsuhiro. Penelitian ini menggunakan metode deskriptif analisis dan metode formal informal. Teori yang digunakan dalam penelitian ini adalah teori psikologi sastra yang dikemukakan oleh Ratna, teori fobia sosial yang dikemukakan oleh Philips, M.D \& dkk, Nevid, A.Rathus dan Greene, teori kognitif perilaku yang dikemukakan oleh Butler dan teori semiotika yang dikemukakan oleh Marcel Danesi. Berdasarkan hasil analisis terdapat delapan gejala fobia sosial yang ada, yaitu 1) Ketakutan atau kecemasan terhadap satu atau lebih situasi sosial; 2) Ketakutan mendapatkan penilaian buruk; 3) Ketakutan atau kecemasan yang bersifat berlebihan; 4) Cenderung menghindari situasi sosial; 5) Ketakutan atau kecemasan tidak sesuai dengan dampak yang ditimbulkan; 6) Ketakutan atau kecemasan berlangsung selama enam bulan atau lebih; 7) Ketakutan atau kecemasan berdampak buruk terhadap kehidupan sehari-hari; 8) Tidak disebabkan oleh efek fisiologis dari suatu zat. Satou Tatsuhiro memenuhi semua gejala fobia sosial tersebut, Faktor penyebab fobia sosial Satou Tatsuhiro karena 1) Faktor kognitif yaitu rasa peka yang berlebihan terhadap suatu ancaman serta pikiran yang irasional dan 2) Faktor sosial budaya yaitu lingkungan sekolah, rumah serta pola asuh. Upaya mengatasi fobia sosial tokoh Satou Tatsuhiro dengan 1) Mengubah pola pikir; 2) Melakukan sesuatu yang berbeda; 3) Mereduksi self consciousness; 4) Membangun kepercayaan diri.
\end{abstract}

Kata kunci : fobia sosial, psikologi sastra, kecemasan

\begin{abstract}
The title of this research is "Social phobia of the character Satou Tatsuhiro in Takimoto Tatsuhiko's Manga NHK ni Youkoso!". The purpose of this research is to know the symptoms and causes of social phobia, and also the efforts done by character Satou Tatsuhiro to overcome his social phobia of Satou Tatsuhiro. The research methods used are descriptive analysis and formal informal methods. There are four theoris used in these research, such as the theory of literature psychology by Ratna, theory of social phobia by Philips, $m$. d. et all, Nevid, a. Rathus and Greene, theory of cognitive behavior by Butler and semiotics theory by Marcel Danesi. Based on the results in this research, there are eight social phobia, such as, 1) The fear or anxiety of one or more social situations; 2) Fear of getting bad judgment; 3) Fear or anxiety is excessive; 4) Tends to avoid social situations; 5) Fear or anxiety is not in accordance with the impact; 6) Fear or anxiety lasts for six months or more; 7) The fear or anxiety have a negative impact on daily life; 8) are not caused by the physiological effects of a substance. Character Satou Tatsuhiro meets all the symptoms of social phobia. These are two factors causing character Satou Tatsuhiro to have social phobia, that are; 1) cognitive factors that taste sensitive to a threat of excessive and irrational thoughts and 2) socio-cultural factors,
\end{abstract}


namely the environment of school, home and parenting. The effort done by character Satou Tatsuhiro to overcome his social phobia are 1) Changing the mindset; 2) doing something different; 3) reduces the self consciousness; 4) Build confidence.

Keywords: social phobia, psychology literature, anxiety

\section{Pendahuluan}

Fobia merupakan perasaan takut dan menghindar terhadap situasi atau objek tertentu yang tidak sebanding dengan resiko yang didapatkan (Nevid dalam Manurung, 2013:10). Fobia sosial dapat terjadi karena memiliki rasa ketakutan yang berlebihan terhadap pandangan negatif dari orang lain. Orang yang menderita fobia sosial selalu merasa bahwa semua orang memandangi dan akan mengevaluasi dirinya secara negatif sehingga mereka cenderung menghindari situasi sosial karena khawatir akan berbuat sesuatu yang memalukan, seperti berbicara di depan publik, bekerja, makan di tempat umum, dan berkencan. (Veale dalam Supramaniam, 2016:3).

Masyarakat Jepang hampir sepuluh sampai dua puluh persennya mengidap penyakit fobia sosial (Lenna, 2014). Maraknya fobia sosial yang terjadi dalam masyarakat Jepang, memunculkan karya sastra yang didalamnya memuat fobia sosial, seperti dalam manga NHK ni Youkoso!. Manga NHK ni Youkoso! ditulis oleh Takimoto Tatsuhiko. Manga ini merupakan adaptasi dari novel yang berjudul NHK ni Youkoso! yang ditulis oleh penulis yang sama. Selain novel, manga ini juga telah diadaptasi ke dalam bentuk anime.

Manga NHK ni Youkoso! yang ditulis oleh Takimoto Tatsuhiko, dipilih sebagai objek penelitian karena tokoh utama Satou Tatsuhiro mengalami fobia sosial dan berupaya untuk mengatasi fobia sosialnya. Penelitian ini dilakukan untuk mengetahui gejala, faktor penyebab dan upaya mengatasi fobia sosial yang dialami Satou Tatsuhiro.

\section{Pokok Permasalahan}

Penelitian ini menganalisis gejala, faktor penyebab dan upaya mengatasi fobia sosial Satou Tatsuhiro dalam manga NHK ni Youkoso!.

\section{Tujuan Penelitian}

Tujuan penelitian ini untuk memberikan pengetahuan kepada masyarakat mengenai fobia sosial. Selain itu, untuk mengetahui gejala, faktor penyebab, dan upaya mengatasi fobia sosial yang dialami tokoh Satou Tatsuhiro dalam manga NHK ni Youkoso! karya Takimoto Tatsuhiko.

\section{Metode Penelitian}

Metode penelitian yang digunakan adalah metode deskriptif analisis. Metode deskriptif analisis dilakukan dengan cara mendiskripsikan fakta-fakta yang kemudian dilanjutkan dengan analisis (Ratna, 2006:53). Data-data yang terdapat dalam manga NHK ni Youkoso! berupa teks percakapan. Setelah data-data yang diperlukan terkumpul, selanjutnya dilakukan analisis sesuai dengan teori yang digunakan, yaitu teori psikologi sastra, teori fobia sosial, teori kognitifperilaku, dan teori semiotika. Teknik penganalisisan data dilakukan dengan menjabarkan data-data yang disertai dengan penjelasan. Selain itu, karena menggunakan objek berupa manga, maka disertakan juga beberapa gambar yang bertujuan untuk mempermudah pemahaman akan data yang ditampilkan tersebut.

\section{Hasil dan Pembahasan}

Dalam penelitian ini akan dijabarkan gejala, faktor penyebab, dan upaya 
mengatasi fobia sosial tokoh Satou Tatsuhiro berdasarkan teori Philips, M. D. \& dkk, Nevid, a. Rathus and Greene, serta Butler. Satou Tatsuhiro merupakan seorang pemuda berusia dua puluh tiga tahun sedang mengalami fobia sosial.

\subsection{Gejala Fobia Sosial}

Gejala fobia sosial Satou Tatsuhiro memiliki delapan kriteria sesuai dengan teori dari Philips, M. D. \& dkk (dalam American Psychiatric Association, 2013:202). Delapan kriteria gejala fobia sosial Satou Tatsuhiro terdiri dari 1) memiliki ketakutan atau kecemasan terhadap satu atau lebih situasi sosial; 2) memiliki ketakutan mendapatkan penilaian buruk dalam situasi sosial; 3) memiliki ketakutan atau kecemasan yang bersifat berlebihan; 4) cenderung menghindari situasi sosial yang menyebabkan ketakutan atau kecemasan; 5) memiliki ketakutan atau kecemasan yang tidak sesuai dengan dampak ditimbulkan oleh situasi sosial; 6) memiliki ketakutan atau kecemasan yang berlangsung selama enam bulam atau lebih; 7) memiliki ketakutan atau kecemasan yang berdampak buruk terhadap kehidupan sehari-hari; 8) memiliki ketakutan atau kecemasan yang tidak disebabkan oleh efek fisiologis dari suatu zat. Berikut ini data dari gejala fobia sosial yang dialami Satou Tatsuhiro.

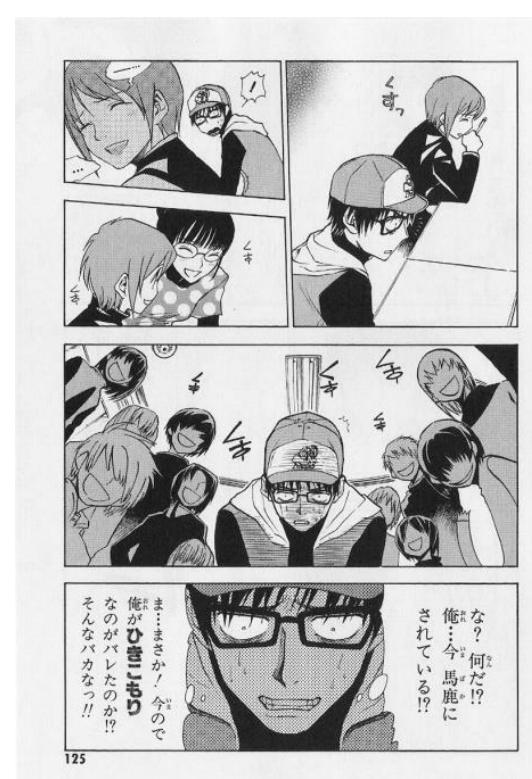

Gambar (1) Satou ketakutan terhadap
penilian buruk

(NHK ni Youkoso! 1, 2004: 125)

Pada gambar (1) Satou merasa sedang dikelilingi oleh semua orang yang berada di kelas dan ditertawakan dengan keras karena kebodohan yang ia lakukan. Butir-butir keringat yang menetes di wajah Satou menandakan bahwa ia sedang ketakutan karena ditertawakan oleh seluruh isi kelas. Padahal kenyataannya mereka hanya tersenyum di tempat duduk masing-masing sambil menertawakan kelucuan Satou. Selain dengan ekspresi, ketakutan Satou juga terlihat pada perkataan Satou seperti berikut:

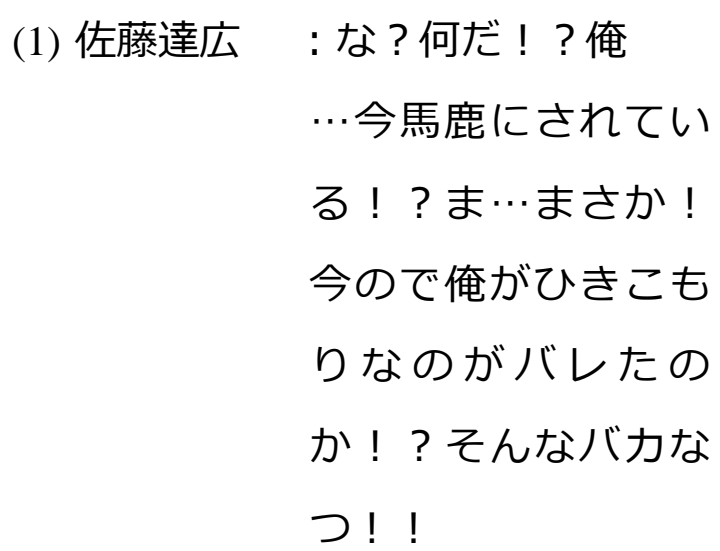


Sato Tatsuhiro : na? nanda!? Ore... ima baka ni sareteiru!? Ma.. masaka! Ima node ore ga hikikomori nano ga baretanoka!? Sonda baka natsu!!

Sato Tatsuhiro : ap? Apa? Aku... sekarang telah melakukan hal bodoh? Tidak mungkin! Semua mengatakan aku mempunyai hikikomori dari percakapan tadi?! Itu tidak mungkin

Pada data (1) memperlihatkan perkataan Satou yang tidak percaya bahwa ia telah melakukan tindakan bodoh. Tindakan bodoh Satou membuat seluruh isi kelas tertawa. Satou merasa seluruh isi kelas sedang menertawakan dan mengatakan hal buruk tentang dia. Karena hal tersebut Satou menjadi ketakutan mendapatkan penilaian buruk.

\subsection{Faktor penyebab Fobia Sosial}

Fobia sosial menurut S. Nevid, A.Rathus dan Greene (dalam Hidayah, 2015:17) dapat disebabkan beberapa faktor diantaranya faktor biologis, faktor kognitif, dan faktor sosio-budaya. Faktor tersebut berdampak pada berkembang atau tidaknya fobia sosial. Pada tokoh Satou Tatsuhiro terdapat dua faktor yang menyebabkan fobia sosial, yaitu faktor kognitif dan faktor sosio-budaya. Berikut akan dijabarkan dua faktor penyebab fobia sosial tokoh Sato Tatsuhiro sebagai berikut:

\subsubsection{Faktor Kognitif}

Faktor ini biasanya dipengaruhi oleh pikiran seseorang. Cara berpikir positif akan mempengaruhi perilaku positif dan sebaliknya, cara berpikir yang negatif akan mempengaruhi perilaku negatif. Perilaku Satou Tatsuhiro dipengaruhi oleh pikiran yang negatif. Pikiran negatif yang dialami Satou Tatsuhiro menyebabkan terjadinya fobia sosial. Faktor kognitif terdiri dari rasa peka yang berlebihan terhadap suatu ancaman dan pikiran yang irasional. Berikut ini data dari faktor kognitif.

（2）佐藤達広 : その致命的なもの

$$
\begin{gathered}
\text { が— 他人とのコミュ } \\
\text { ニケーションだ... }
\end{gathered}
$$

Satou Tastuhiro : Sono chimeiteki na mono ga--- tannin to no komyunikeeshon da..

Satou Tatsuhiro : Hal yang menakutkan-- berbicara dengan orang...

Pada data (2) memperlihatkan Satou sedang berpikiran irasional dengan mengatakan bahwa berbicara dengan orang adalah hal yang menakutkan. Satou telah lama tidak berbicara dengan orang asing sehingga timbul pemikiran seperti itu dan menganggap berbicara dengan orang menakutkan. Karena pikiran irasional Satou seperti itu menyebabkan Satou berperilaku negatif ke orang asing tersebut.

\subsubsection{Faktor Sosial Budaya}

Faktor sosial budaya yang menyebabkan fobia sosial di antaranya adalah lingkungan, pola asuh keluarga, ekonomi, pendidikan, kesehatan. Penyebab fobia sosial Satou Tatsuhiro dalam faktor sosial budaya yang paling mempengaruhi ialah lingkungan dan pola asuh keluarga. Berikut ini data yang menggambarkan situasi tersebut.

(3) 近所の人：やだ！ちょつと 
アレ見た？最低！

ほんどうバカみた

い町を歩かないて

欲しいわあ...

Kinjo no hito: Yada! Chotto are mita? Saitei! Hondou baka mitai machi wo arukanaite hoshii waa

Tetangga : oh tidak! Apakah

kamu melihat itu?

Buruk!Benar-benar bodoh. Saya harap dia tidak jalan di sekitar

kota ini seperti itu

Pada data (3) terlihat perkataan dari salah satu orang yang sedang bergunjing ketika Satou hendak pulang ke wisma. Satou merasa orang-orang tersebut sedang membicarakan dia karena sebelumnya Satou telah melakukan hal bodoh yang membuat ia ditertawakan seluruh kelas. Semenjak kejadian tersebut Satou menjadi takut ketika keluar rumah dan memilih keluar pada tengah malam untuk belanja keperluan sehari-hari demi mengindari orang-orang yang akan bergunjing tentang dia.

\subsection{Upaya Mengatasi Fobia Sosial}

Upaya mengatasi fobia sosial tokoh Satou Tatsuhiro dilakukan dengan terapi kognitif-perilaku. Terapi kognitifperilaku menurut Butler (dalam Asrori, 2015:94) terdiri dari empat tahap yaitu mengubah pola pikir, melakukan sesuatu yang berbeda, mereduksi selfconciousness, dan membangun kepercayaan diri. Berikut ini contoh data upaya mengatasi fobia sosial tokoh Satou Tatsuhiro.

（4）佐藤達広：・尚や俺もすぐ働
くから安心してよ！！

多分あと一、二週間も

すればすぐ復活するか

$5 ! !$

Satou Tatsuhiro : $\cdots$ iya ore mosugu hataraku kara anshin shiteyo!! Tabun ato ichi, ni shuukan mo sureba sugu fukkatsu surekara!!

Satou Tatsuhiro : $\cdots$ jadi sekarang aku akan mulai bekerja secepatnya jadi jangan khawatir!! Mungkin setelah beberapa minggu aku akan kembali normal!!

Pada data (4) Satou mengatakan katakata yang positif pada dirinya sendiri bahwa ia akan mulai bekerja dan sembuh dari fobia sosial beberapa minggu lagi dalam perjalanan menuju ke rumah orang tuanya. Satou kembali pulang ke rumah orang tuanya karena orang tuanya mengetahui bahwa Satou dikeluarkan dari kampus dan tidak bekerja. Pada awalnya Satou menolak untuk pulang ke rumah orang tuanya namun pada akhirnya ia senang melihat lingkungan rumah orang tuanya tidak berubah ia merasa seperti sedang bernostalgia. Satou merasakan bahwa di rumah orang tuanya ia akan sembuh dari fobia sosial.

\section{Simpulan}

Seseorang dapat dikatakan memiliki fobia sosial apabila dapat memenuhi semua kriteria gejala fobia sosial yang ada. Satou Tatsuhiro memenuhi semua kriteria gejala fobia sosial tersebut. Faktor penyebab fobia sosial Satou Tatsuhiro dalam penelitian ini, faktor 
biologis tidak menyebabkan Satou Tatsuhiro mengalami fobia sosial. Pada upaya mengatasi fobia sosial, mengubah pola pikir merupakan tahap yang paling berpengaruh bagi Satou Tatsuhiro dalam upaya mengatasi fobia sosialnya karena dengan tahap tersebut Satou perlahan mulai sembuh dari fobia sosialnya.

\section{Daftar Pustaka}

American Psychiatric Association. 2013. Diagnostic And Statistical Manual of Mental Disorder 5th Edition "DSM-5". Washington DC: American Psychiatric Publishing

Asrori, Adib. 2015. Jurnal Ilmiah Psikologi Terapan, Vol. 3, no. 01. Malang: Universitas Muhammadiyah Malang

Hidayah, Nur Wahyu. 2015. Problem Kejiwaan Tokoh Utama dalam Novel Pasung Jiwa karya Okky Madasari. Yogyakarta: Universitas Negeri Yogyakarta.

Lenna. 2014. Taijin Kyofusho - a Very "Japanese" Social Anxiety. https://www.tofugu.com (Diakses pada tanggal 4 April 2016).

Manurung, Nazwa. 2013. Terapi Rasional Emotif Tingkah Laku Pada Anak Dengan Fobia Spesifik "Nasi" (Rational Emotive Behavior Therapy for a Child with Specific Phobia "Rice") (Tesis). Sumatera Utara. Universitas Sumatera Utara.

Ratna, Nyoman Kutha. 2006. Teori, Metode, dan Teknik Penelitian Sastra. Yogyakarta: Pustaka Pelajar.

Supramaniam, Prabu. 2013. Jurnal Medika Udayana, Vol. 2, no. 11, pp. 1843-1861. Denpasar: Universitas Udayana 